\title{
Audiological Abnormalities in Vitiligo Patients: A Hospital-Based Cross-Sectional Study
}

\author{
Neel Prabha ${ }^{1}$ Ripudaman Arora ${ }^{2}$ Namrata Chhabra ${ }^{1}$ Monalisa Jati ${ }^{2}$ Nitin M. Nagarkar ${ }^{2}$
}

\footnotetext{
${ }^{1}$ Department of Dermatology, Venereology and Leprology, All India Institute of Medical Sciences, Raipur, Chhattisgarh, India

2 Department of ENT \& HNS, All India Institute of Medical Sciences, Raipur, Chhattisgarh, India
}

\begin{abstract}
Address for correspondence Dr Ripudaman Arora, MBBS, MS, All India Institute of Medical Sciences, GE Rd, Tatibandh, Raipur, Chhattisgarh, India (e-mail: neelripu@gmail.com).
\end{abstract}

Int Arch Otorhinolaryngol 2020;24:e149-e153.

\begin{abstract}
Introduction There are some discrepancies in the literature about the influence of vitiligo on auditory functions. According to some authors, vitiligo influences hearing, whereas others question such influence. Therefore, we conducted a study to evaluate audiological functions in vitiligo patients.

Objectives To determine the effect of vitiligo on auditory functions.

Methods A hospital-based observational study was done from January 2017 to July 2017. Clinically diagnosed cases of vitiligo were enrolled for the study. A complete otological examination was conducted in all patients.

Results Fifty-two patients (male: female 28:24) were included in the study. Ten patients (19.2\%) had sensorineural hearing loss (SNHL). Seven patients (13.5\%) had bilateral and $3(5.7 \%)$ had unilateral SNHL. High frequency loss was seen in 17 out of 20 ears (10 affected patients), 6 ears had both low and high-frequency hearing loss. Of 12 ears with speech frequency involvement, mild hearing loss was seen in 5 and moderate

Keywords

- vitiligo

- sensorineural hearing loss

- audiological functions to severe in 1 ear. Most cases of SNHL were detected in the age group 41 to 60 years old (63.6\%), which was statistically significant ( $p$-value 0.00 ).

Conclusion The results of this study suggest that vitiligo patients require routine monitoring for auditory functions for early identification of SNHL. Older subjects with vitiligo might be at a higher risk for audiological abnormalities. These patients should also be informed regarding the associated risk with noise and ototoxic drug exposure.
\end{abstract}

\section{Introduction}

Vitiligo is an acquired discoloration of skin caused by loss or damage of epidermal melanocyte and characterized by well-defined depigmented macules. It occurs worldwide with an overall prevalence of $1 \% .^{1}$ In a study from India, the point prevalence was 9.982 from four zones of India namely North, South, East and West on 20 November $2012 .^{2}$ Adults and children of both genders are equally affected, and the greater number of reports among females could be explained by the social consequences to females affected by vitiligo. $^{1}$ Almost $50 \%$ of vitiligo patients present with symptoms before 20 years of age and nearly 70 to $80 \%$ before 30 years of age. ${ }^{1}$

The exact etiology of vitiligo is not known. However, genetic, neural, immunological and self-destructive pathomechanisms are said to be involved. Autoantibodies are directed against the antigens of melanocytes, which lead to the destruction of melanocytes. Melanocytes are located in the epidermis, hair bulbs, uveal tract, retinal pigmented epithelium, leptomeninges, and inner ear.

Hence, the mechanisms responsible for the destruction of melanocyte in the skin affect melanocytes in other locations as received

December 18, 2018

accepted

July 1, 2019
DOI https://doi.org/

10.1055/s-0039-1696700. ISSN $1809-9777$.
Copyright $\odot 2020$ by Thieme Revinter

Publicações Ltda, Rio de Janeiro, Brazil
License terms

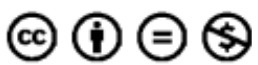


well. There are some discrepancies in the literature about the influence of vitiligo on auditory functions. According to some authors, vitiligo influences hearing, ${ }^{3-9}$ whereas others question such influence. ${ }^{10-13}$ Accordingly, this study was designed to evaluate the audiological functions in vitiligo patients.

\section{Materials and Methods}

A hospital-based prospective observational study was done from January 2017 to July 2017 after obtaining permission from the institutional ethics committee. After obtaining a written informed consent, clinically diagnosed cases of vitiligo patients were enrolled for the study. The demographic profile, duration and evolution of vitiligo, personal and family history, medical history, cutaneous and otological examination were recorded in a predesigned proforma. Pregnant females, history or evidence of otological disease, documented hearing loss, familial hearing loss, ototoxic drug intake, chronic exposure to noise, neurological, vascular, or systemic diseases, such as diabetes and hypertension, were excluded.

A complete otological examination was conducted in all patients by an otorhinolaryngologist. Otological examination included external examination, tuning fork and pure tone audiometry. Audiological evaluation was performed in a sound-treated room using a single-channeled audiometer. The audiometer, which was used for threshold estimation, was Triveni-TAM-500ME (Andheri, Mumbai, India). Both airconduction thresholds and bone-conduction thresholds were measured. The thresholds (minimum level of hearing) for air conduction were estimated using standard headphone TDH39 (770 Park Ave, Huntington, NY11743, US), from frequency range $250 \mathrm{~Hz}$ to $8 \mathrm{KHz}$, with intensity level -10 $\mathrm{dBHL}$ to $120 \mathrm{dBHL}$, and the pure tone average was measured using an average of three frequencies, that is, $500 \mathrm{~Hz}, 1 \mathrm{KHz}$, and $2 \mathrm{KHz}$. Bone conduction was tested with test frequencies from $250 \mathrm{~Hz}$ to $4 \mathrm{KHz}$, with intensity level from -10 dBHL to $70 \mathrm{dBHL}$ (with standard bone conductor B71, Radio ear, Audiometer alle1, 5500 Middelfart, Denmark). For measuring hearing thresholds at higher frequencies above $8 \mathrm{KHz}$, MAICO MA 42 (Sicklinggenstr. 70-71, 10553 Berlin, Germany), a dual channel audiometer was used. The MAICO MA42 audiometer delivers test frequencies from $125 \mathrm{~Hz}$ to 20 $\mathrm{KHz}$, with intensity levels from $-10 \mathrm{dBHL}$ to $120 \mathrm{dBHL}$.

For degree of hearing loss, the following scale was used: minimal $>16$ to $25 \mathrm{~dB}$; mild $>25$ to $40 \mathrm{~dB}$; moderate $>40$ to $55 \mathrm{~dB}$; moderate to severe $>55$ to $70 \mathrm{~dB}$; severe $>70$ to $90 \mathrm{~dB}$; and profound $>90 \mathrm{~dB}$ hearing loss

The data analysis was done with the help of the statistical software SPSS version 25 (IBM Corp., Armonk, NY, USA). The data was summarized using descriptive statistics, frequencies, and percentage. Statistical differences between categorical variables were assessed using the Chi-square test. A $p$-value $<0.05$ was considered statistically significant.

\section{Results}

Fifty-two patients (male: female 28:24) were included in the study. The clinico-epidemiological profile of vitiligo
Table 1 Sensorineural hearing loss in relation to age, age of onset, gender, vitiligo type and site of onset

\begin{tabular}{|c|c|c|c|}
\hline Age group & $\begin{array}{l}\text { Number } \\
\text { of cases } \\
\text { with SNHL } \\
(\%)\end{array}$ & $\begin{array}{l}\text { Number } \\
\text { of cases } \\
\text { without } \\
\text { SNHL (\%) }\end{array}$ & $p$-value $=0.00$ \\
\hline $1-20$ years & $1(5.3)$ & $18(94.7)$ & \\
\hline $21-40$ years & $2(9.1)$ & $20(90.9)$ & \\
\hline $41-60$ years & $7(63.6)$ & $4(36.4)$ & \\
\hline \multicolumn{3}{|l|}{ Age of onset } & \multirow[t]{6}{*}{$p$-value $=0.598$} \\
\hline $1-10$ years & $1(7.7)$ & $12(92.3)$ & \\
\hline $11-20$ years & $2(11.1)$ & $16(88.9)$ & \\
\hline $21-30$ years & $0(0)$ & $6(100)$ & \\
\hline $31-40$ years & $2(28.6)$ & $5(71.4)$ & \\
\hline$>40$ years & $5(62.5)$ & $3(37.5)$ & \\
\hline \multicolumn{3}{|l|}{ Gender } & \multirow[t]{3}{*}{$p$-value $=0.065$} \\
\hline Male & $8(28.6)$ & $20(71.4)$ & \\
\hline Female & $2(8.3)$ & $22(91.7)$ & \\
\hline \multicolumn{4}{|l|}{ Vitiligo type } \\
\hline Vitiligo vulgaris & $4(21.1)$ & 15 (78.9) & \multirow[t]{8}{*}{$p$-value $=0.863$} \\
\hline Acrofacial & $2(20.0)$ & $8(80.0)$ & \\
\hline Facial & $1(11.1)$ & $8(88.9)$ & \\
\hline Acral & $2(28.6)$ & $5(71.4)$ & \\
\hline Focal & $0(0)$ & $3(100)$ & \\
\hline Mucosal & $0(0)$ & $1(100)$ & \\
\hline Vitiligo universalis & $1(50)$ & $1(50)$ & \\
\hline Segmental & $0(0)$ & $1(100)$ & \\
\hline \multicolumn{3}{|l|}{ Site of onset } & \multirow[t]{6}{*}{$p$-value $=0.791$} \\
\hline Head and neck & $3(13.6)$ & $19(86.4)$ & \\
\hline Lower limb & $2(16.7)$ & $10(83.3)$ & \\
\hline Upper limb & $2(22.2)$ & $7(77.8)$ & \\
\hline Trunk & $2(33.3)$ & $4(66.7)$ & \\
\hline Mucosa & $1(33.3)$ & $2(66.7)$ & \\
\hline
\end{tabular}

Abbreviations: F, female; M, male; SNHL, sensorineural hearing loss.

Table 2 Duration of vitiligo

\begin{tabular}{|l|l|}
\hline Duration of vitiligo & Number of cases (\%) \\
\hline $1-6$ months & $11(21.1)$ \\
\hline 6 months -1 year & $6(11.5)$ \\
\hline $1-5$ years & $17(32.7)$ \\
\hline $5-10$ years & $9(17.3)$ \\
\hline$\geq 10$ years & $9(17)$ \\
\hline
\end{tabular}

patients is shown in - Tables 1 and 2. The mean age of patients was 26.7 years, ranging from 7 years to 60 years. The mean age of onset of vitiligo was 21.7 years, ranging from 4 years to 50 years. Eight patients (15.3\%) had positive family history and included first-degree relatives in 4 (7.6\%), second-degree relatives in $3(5.7 \%)$ patients, and 
both first and second-degree relatives in 1 (1.9\%) patient. Fifty-one patients (96\%) had non-segmental vitiligo, and vitiligo vulgaris was the most common clinical type.

Audiological examination was done in all patients. Ten patients (19.2\%) had sensorineural hearing loss (SNHL). Details of vitiligo patients with SNHL are shown in - Table 3. Seven patients (13.5\%) had bilateral and 3 (5.7\%) had unilateral SNHL. High frequency loss was seen in 17 out of 20 ears ( 10 affected patients), 6 ears had both low and high-frequency hearing loss. Of 12 ears with speech frequency involvement, mild hearing loss was seen in 5 ears and moderate to severe in 1 ear. The pattern of hearing loss and details of vitiligo are shown in - Table 3.

Most cases of SNHL were detected in age group 41 to 60 years $(63.6 \%)$, which was statistically significant ( $p$-value 0.00 ). Sensorineural hearing loss was present in 5 out of 10 patients (66.7\%) having vitiligo for less than 5 years, and 5 out of $32(86.5 \%)$ for more than 5 years.

\section{Discussion}

The otic melanocytes are located in the stria vascularis, hair cells, endolymphatic sac, and vestibular organ. ${ }^{14}$ The function of these melanocytes are not exactly known. In the stria vascularis, otic melanocytes modulate the function of $\mathrm{Na}^{+} / \mathrm{K}^{+}$-ATPase and potassium channels, which are essential for creating endocochlear electrical potential. ${ }^{15}$ The electrical activity of ciliary cells in the labyrinth is closely connected with their physiological ability to send afferent information to brain areas involved in auditory and balance functions.

Ardic et $\mathrm{al}^{16}$ noticed lower pure tone thresholds at higher sound frequencies (from 4,000-16,000 Hz) in patients with vitiligo. Based on their observations, as well as the fact that social and environmental damage affects hearing at the same sound frequencies, the authors suggested a preventive role of melanocytes for the sensitive inner ear cells. Murillo-Cuesta et al ${ }^{17}$ also stated that otic melanocytes do not appear to be essential for normal hearing, but they are assumed to play a protective role against environmental damage. In the present study, lower pure tone thresholds at higher sound frequencies (from $4,000-8,000 \mathrm{~Hz}$ ) were also found in 17 ears of 10 affected vitiligo patients, which also favors the theory of the protective role of otic melanocytes.

The exact site of damage that leads to hearing impairment in vitiligo is not known. Aydogan et $\mathrm{al}^{5}$ observed that patients with vitiligo have disturbances in the upper part of the auditory pathway, in the cranial nerve VIII, and above the level of the cochlear nuclei in pons. Sydlowski et $\mathrm{al}^{18}$ postulated that successful cochlear implantation in patients with auditory symptoms concurrent with autoimmune destruction of melanocytes might be the evidence for cochlear localization of hearing injury related to vitiligo. Anbar et $\mathrm{al}^{19}$ found that 64 ears (60\%) of patients with vitiligo had cochlear dysfunction. As observed in the present study as well as in various other studies, vitiligo patients display hearing loss at high frequency, which suggests that the basal turns of cochlea are probably affected more in

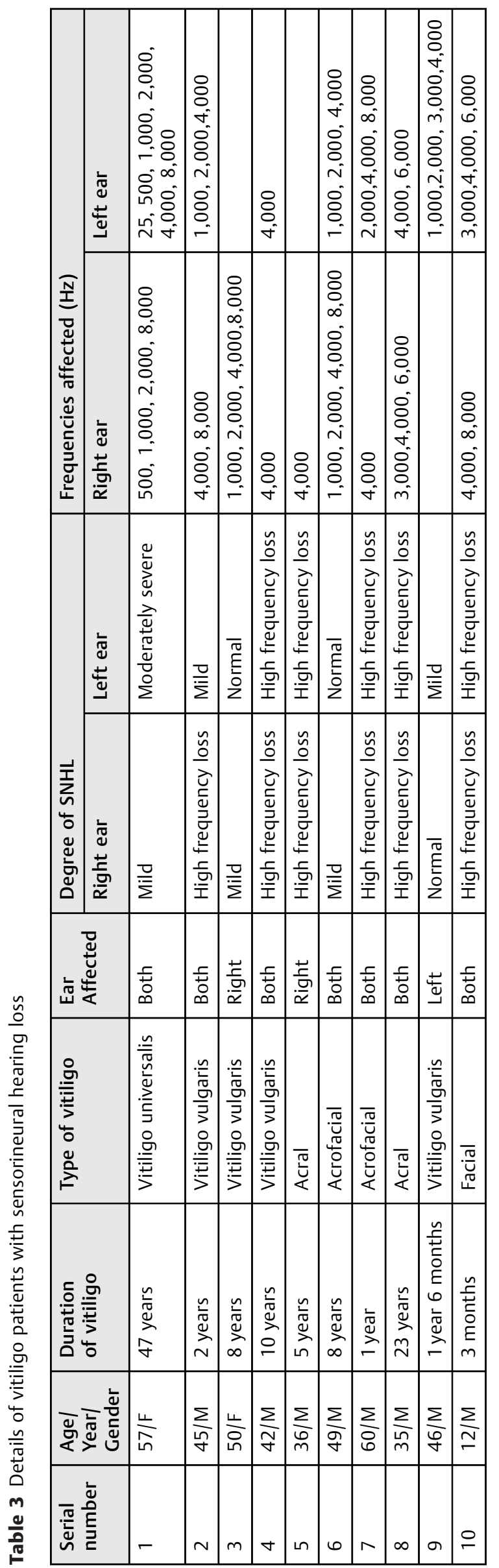


vitiligo. Mahdi et $\mathrm{al}^{20}$ and Dawoud et $\mathrm{al}^{21}$ found, in addition to auditory affection, peripheral vestibular disorders in vitiligo patients.

Sensorineural hearing loss has been reported in 4 to $37 \%$ of patients with vitiligo. ${ }^{3-9}$ In the present study, 10 patients (19.2\%) had SNHL. These patients were asymptomatic but, on audiological evaluation, were diagnosed with hearing loss. Conductive deafness was found in two studies. ${ }^{4,22}$ However, in the present and other studies, only SNHL was seen. Conductive loss in vitiligo is unlikely, as melanocytes do not take part in conductive mechanism of hearing since they are only present in inner ear. Conductive hearing loss can only be seen in a vitiligo if there is any coexisting middle ear pathology. On the other hand, other studies have not found audiological abnormalities in vitiligo patients. ${ }^{10-13}$ This controversy could be due to the use of different selection criteria and methodology among studies.

Gopal et $\mathrm{al}^{22}$ suggested that the hearing loss could result from other autoimmune diseases coexisting with vitiligo, such as diabetes mellitus and hypothyroidism. However, in the present study and other studies, hearing loss was seen in patients without autoimmune and/or other metabolic diseases. $^{13,14}$ In our study, SNHL was found to be significantly higher in the older age group (41-60 years). The minimum age of patients with SNHL was 12 years, and the maximum age was 60 years. Shankar et $\mathrm{al}^{23}$ found that the $>30$ years old age group was significantly associated with abnormal auditory findings. However, Sharma et al did not observe any association between age and SNHL in vitiligo. ${ }^{4}$ The association in our study could be due to the fact that we have included all age groups, unlike the study by Sharma et $\mathrm{al}^{4}$, in which only the age group of 5 to 40 years was included.

Similar to the study by Ardic et al, $^{16}$ in our study, male subjects were predominantly affected by SNHL when compared with female subjects. Whereas other researchers found a higher incidence of hearing loss in female patients ${ }^{24}$ or equal incidence in both sexes. ${ }^{4,23}$ Similar to Maheshwari et al, ${ }^{14}$ we also noticed a $50 \%$ incidence of SNHL in patients affected by vitiligo universalis. Hong et $\mathrm{al}^{6}$ noticed an association of SNHL with non-segmental vitiligo, while Sharma et $\mathrm{al}^{4}$ and Mohamed et $\mathrm{al}^{9}$ reported generalized vitiligo as a risk factor.

Similar to other studies, we could not find any significant association between SNHL and duration of vitiligo. ${ }^{4,9,20}$ According to Mahdi et al, ${ }^{20}$ this could be explained by the possibility that otic melanocytes are affected at the start of vitiligo and then stabilize afterwards. However, in contrast to this, Aslan et $\mathrm{al}^{8}$ and Ardic et $\mathrm{al}^{16}$ found a statistically significant association between the duration of vitiligo and hearing loss.

Maheshwari et $\mathrm{al}^{14}$ reported that vitiligo originating in the head and neck region was strongly associated with hearing loss (54.55\%, 6 of 11 cases). In our study, the site of onset was the head and neck in $30 \%$ of the cases with SNHL; however, we could not find a statistically significant association.

\section{Conclusion}

The results of this study suggest that vitiligo patients require routine monitoring for auditory functions for early identification of sensorineural hearing loss. Older subjects with vitiligo might be at a higher risk for audiological abnormalities. These patients should also be informed regarding the associated risk with noise and ototoxic drug exposure.

Source(s) of support

None to be declared.

Conflicts of Interest

The authors have no conflicts of interest to declare.

\section{References}

1 Sehgal VN, Srivastava G. Vitiligo: compendium of clinico-epidemiological features. Indian J Dermatol Venereol Leprol 2007;73 (03):149-156

2 Kumar S, Nayak CS, Padhi T, et al. Epidemiological pattern of psoriasis, vitiligo and atopic dermatitis in India: Hospitalbased point prevalence. Indian Dermatol Online J 2014;5(Suppl 1): S6-S8

3 Ozüer MZ, Sahiner T, Aktan S, Sanli B, Bayramoğlu I. Auditory evoked potentials in vitiligo patients. Scand Audiol 1998;27(04): 255-258

4 Sharma L, Bhawan R, Jain RK. Hypoacusis in vitiligo. Indian J Dermatol Venereol Leprol 2004;70(03):162-164

5 Aydogan K, Turan OF, Onart S, Karadogan SK, Tunali S. Audiological abnormalities in patients with vitiligo. Clin Exp Dermatol 2006;31 (01):110-113

6 Hong CK, Lee MH, Jeong KH, Cha CI, Yeo SG. Clinical analysis of hearing levels in vitiligo patients. Eur J Dermatol 2009;19(01): 50-56

7 Akay BN, Bozkir M, Anadolu Y, Gullu S. Epidemiology of vitiligo, associated autoimmune diseases and audiological abnormalities: Ankara study of 80 patients in Turkey. JEur Acad Dermatol Venereol 2010;24(10):1144-1150

8 Aslan S, Serarslan G, Teksoz E, Dagli S. Audiological and transient evoked otoacoustic emission findings in patients with vitiligo. Otolaryngol Head Neck Surg 2010;142(03):409414

9 Mohamed ES, Said EA, Sayed DS, Awad SM, Ahmed MH. Auditory system dysfunction in patients with vitiligo: is it a part of a systemic autoimmune process? Egypt J Otolaryngol 2017;33(03): 594-602

10 Tosti A, Bardazzi F, Tosti G, Monti L. Audiologic abnormalities in cases of vitiligo. JAm Acad Dermatol 1987;17(2 Pt 1): 230-233

11 Escalante-Ugalde C, Poblano A, Montes de Oca E, Lagunes R, Saúl A. No evidence of hearing loss in patients with vitiligo. Arch Dermatol 1991;127(08):1240

12 Elsaied MA, Naga YAA, Abdo IM. Evaluation of brain stem evoked response in vitiligo patients. JPan Arab League Dermatol 2008; 19:91-97

13 AlGhamdi KM, Khurrum H, Al-Momani MO, Hagr A. Assessment of audiological abnormalities in vitiligo patients. Otorinolaringol 2017;67(02):39-43

14 Maheshwari A, Panigrahi R, Mahajan S. Vitiligo associated hypoacusis: a case control study. Int J Otorhinolaryngol Head Neck Surg 2016;2(02):77-81

15 Tachibana M. Cochlear melanocytes and MITF signaling. J Investig Dermatol Symp Proc 2001;6(01):95-98 
16 Ardiç FN, Aktan S, Kara CO, Sanli B. High-frequency hearing and reflex latency in patients with pigment disorder. Am J Otolaryngol 1998;19(06):365-369

17 Murillo- Cuesta S, Contreras J, Zurita E, Cediel R, Cantero M, Varela-Nieto I, et al. Melanin precursors prevent premature age related and noise induced hearing loss in albino mice. Pigm Cell melanoma Res 2010;23(01):72-83

18 Sydlowski SA, Luffler C, Haberkamp T. Successful cochlear implantation in a case of Vogt-Koyanagi-Harada disease. Otol Neurotol 2014;35(09):1522-1524

19 Anbar TS, El-Badry MM, McGrath JA, Abdel-Azim ES. Most individuals with either segmental or non-segmental vitiligo display evidence of bilateral cochlear dysfunction. Br J Dermatol 2015; 172(02):406-411
20 Mahdi P, Rouzbahani M, Amali A, Rezaii Khiabanlu S, Kamali M. Audiological manifestations in vitiligo patients. Iran J Otorhinolaryngol 2012;24(66):35-40

21 Dawoud EAE, Ismail EI, Eltoukhy SA-G, El-Sharabasy AE-S. Assessment of auditory and vestibular functions in vitiligo patients. JOtol 2017;12(03):143-149

22 Gopal KV, Rama Rao GR, Kumar YH, Appa Rao MV, Vasudev P; Srikant. Vitiligo: a part of a systemic autoimmune process. Indian J Dermatol Venereol Leprol 2007;73(03):162-165

23 Shankar DS, Shashikala K, Madala R. Clinical patterns of vitiligo and its associated comorbidities. Indian J Dermatol 2012;3(02): 114-118

24 Sharifian MR, Maleki M, Honarvar H. The correlation between vitiligo and hearing loss. Iran J Otorhinolaryngol 2006;17(42):3-8 